\title{
The Effects of Physical Properties of Fibers in Nettle Fiber/Polyester Composites on the Thermal Conductivity Coefficient
}

\author{
${ }^{1}$ Murat KORU and ${ }^{* 2}$ Kenan BÜYÜKKAYA \\ ${ }^{1}$ Isparta Uygulamalı Bilimler University, Isparta/Turkey, muratkoru@sdu.edu.tr \\ ${ }^{* 2}$ Giresun University, Giresun/Turkey, Kenan.buyukkaya@giresun.edu.tr
}

\begin{abstract}
The physical properties of the materials used are also important in the thermal conduction, besides many other factors. In this study, nettle fiber/polyester composites were formed using stinging nettle grown in the Black Sea region. The stinging nettle fibers used in the formation of these composites were divided into three parts as bottom, middle, and top. The physical properties (diameter, density, crystallinity) of the fibers obtained from different parts of the plant and how the increased fiber concentration affected the thermal conductivity coefficients of the composite materials formed were studied. As a result, it was observed that the thermal conductivity coefficients of the composites increased with the increase of the crystallinity ratio of the fiber. Moreover, the increased fiber concentration significantly increased the thermal conductivity coefficient of the composite materials produced.
\end{abstract}

Key words: Nettle fiber, polyester, heat conduction, physical properties, composite.

\section{Introduction}

The interest in composites made of plant fibers continues to increase recently. The primary reasons for this interest in the fibers are being environmentally friendly, bio degradability, lightness, low cost, high specific properties, easy processability, easy accessibility, and resistance to abrasion. Plant fibers are widely used as an effective reinforcing material in polymer composites owing to their advantageous properties [1-3].

In the previous studies, the fibers obtained from different plants were used to produce composites and the thermal properties of these composites were investigated. In this context, Mangal et al. [4] reported that with the increase in fiber content of the fiber-reinforced PF composites obtained from pineapple leaves, thermal conductivity and thermal diffusion decreased, and this depended on the fiber concentration in the matrix. Onesippe et al. [5] investigated the thermal properties of the cement composites reinforced with herbal bagasse fibers. The experimental studies showed that the addition of bagasse fibers reduced the thermal conductivity of the composites, and produced lower specific heat than composites made of alkaline bagasse fibers.

*Corresponding author: Address: Vocational School of Technical Sciences, Department of Machine and Metal Technologies, Giresun University, 28049/GIRESUN, TURKEY. E-mail address: kenan.buyukkaya@giresun.edu.tr, Phone: +904543101531 
Qi et al. [6] stated that the sorghum that was mixed at a ratio of $40 \%$ at maximum into sorghum/HDPE composites reduced the thermal conductivity coefficient. Osigu el al. [7] reported that the increasing voids within the composite due to the increase in the concentration provided an excellent thermal insulation effect, and therefore, this reduced the thermal conductivity coefficient of the composite.

In this study, composites were formed by adding stinging nettle fibers obtained from different parts (from the bottom, middle and top parts of the plant) to the polyester matrix. The thermal conductivity coefficient of the composites formed were determined by the amount of reinforcement added and the physical properties of the fibers (crystallinity and density). According to the findings obtained, the thermal conductivity coefficient of the composites increased in parallel with the increase of crystallinity ratio of the fibers. With the increase in the fiber ratio in composites, the thermal conductivity coefficient decreased partially in the beginning, but then the thermal conductivity value increased.

\section{Materials and Method}

\subsection{Material}

The nettle fiber was obtained from the stinging nettle (Urtica dioica L.) which naturally grows in the Black Sea Region. The mechanical method was used to obtain the fibers. The fibers that were cut approximately $0.5 \mathrm{~mm}$ in size with an industrial chopper were used in producing composites. The polyester matrix material (UN1866) used for the formation of composites was provided from Poliya company. Cobalt and MEK-P (Methyl-Ethyl-Ketone Peroxide) were used to cure the polyester matrix material. The accelerator and hardener ratios were $6 \%$ Cobalt $1 \%$ from $0.1 \%$ MEK-P over the polyester mass. Some mechanical properties of the standard polyester are given in Table 1 [8].

Table: 1 The mechanical and physical properties of polyester in solid state.

\begin{tabular}{cccccccc}
\hline $\begin{array}{c}\text { Bending } \\
\text { Strength }\end{array}$ & $\begin{array}{c}\text { Bending } \\
\text { Mod. }\end{array}$ & $\begin{array}{c}\text { Elongation } \\
\text { ratio }\end{array}$ & $\begin{array}{c}\text { Tensile } \\
\text { Strength }\end{array}$ & $\begin{array}{c}\text { Tensile } \\
\text { Mod. }\end{array}$ & $\begin{array}{c}\text { Tensile } \\
\text { elongation }\end{array}$ & Impact & Density \\
\hline 145 & 4800 & $5.5 \%$ & 57 & 2950 & 2.6 & 10 & 1.1 \\
$\mathrm{MPa}$ & $\mathrm{MPa}$ & & $\mathrm{MPa}$ & $\mathrm{MPa}$ & $\%$ & $\mathrm{~kJ} / \mathrm{m} 2$ & $\mathrm{gr} / \mathrm{cm} 3$ \\
\hline
\end{tabular}

Composites were formed by adding reinforcement material consisting of carded fibers and coarse fibers at 2.5, 5, 7.5 and $10 \%$ weight ratios to the matrix material. The untreated test samples were obtained by pouring the prepared liquid mixture into molds. Then, the mixture was kept in the oven at $80^{\circ} \mathrm{C}$ for 24 hours for final curing. Its surfaces were levelled with the sanding machine and made ready for the test (Figure 1). 


\subsection{Physical tests}

An optical microscope (OLYMPUS BX 53) was used to determine the diameters of the fibers. Fifty fibers from all three parts were measured to determine the diameter range and mean diameters.

$\mathrm{X}$-Ray diffraction test was performed using copper-radiation advanced diffractometer (Europe 600 $\mathrm{XRD}$ ). The device was run at $\mathrm{Cu} \mathrm{Ka}, 40 \mathrm{kV}$ and $30 \mathrm{~mA}$. The scanning range was 10-30, interval was 0.02 , and scanning rate was set to $0.4 \mathrm{~min}-1$. The pycnometer method was used to determine the density of nettle fibers. In this method, acetone was used as the liquid. Scanning electron microscopic images were obtained using JEOL Ltd.'s JSM-5910 after the gold-plating procedure. SEM analysis was performed by examining the fractured surfaces of nettle fiber /PMMA composites in detail. The crystallinity index (CrI) of nettle fiber was determined using Segal empirical method.22 This method enables the rapid and simple calculation of crystallinity index via the equation below. Here, I002 is the maximum point of the peak of Crystal (002), while Iam is the minimum point of amorphous material between peaks (101) and (002).

$\mathrm{CrI}=(\mathrm{I} 002-\mathrm{Iam}) \times 100 / \mathrm{I} 002$

\subsection{Determination of Thermal Conductivity ( $(\lambda)$}

Thermal conductivity dependent on different content samples has been measured by a Lasercomp HFM Fox-50 heat flow meter device measuring under the conditions given in ASTM C518, EN 12664 and ISO 8301 standards. The working principle of this device is given in Fig. 1.

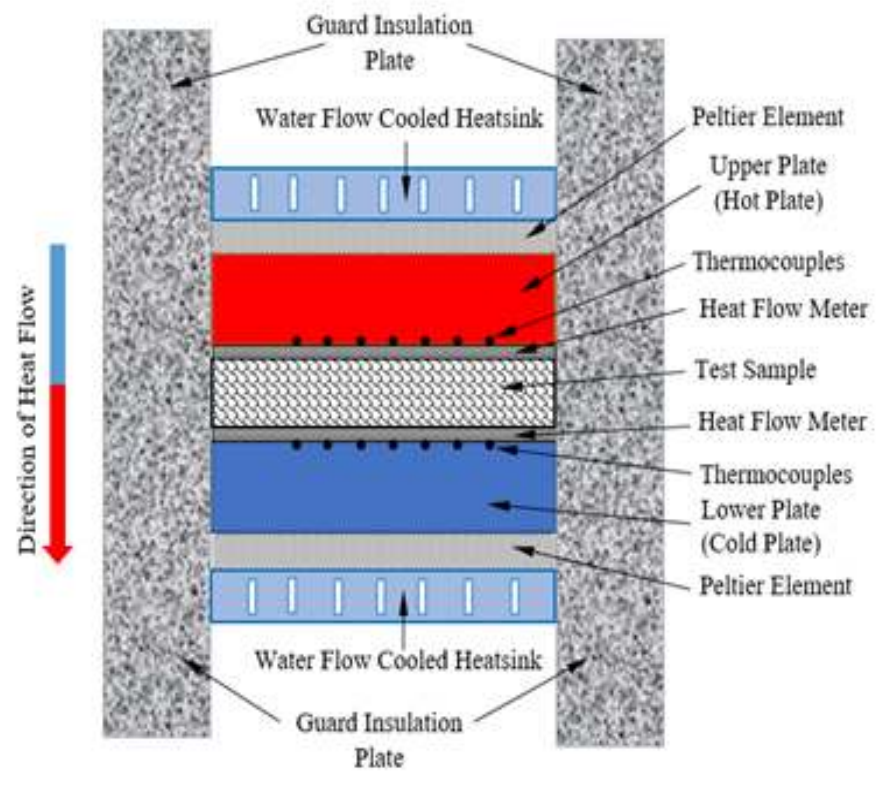

Fig. 1- Schematic diagram of heat flow meter 
When performing the test by HFM device, a sample is settled between two plates with different temperatures. These plates are kept at a constant temperature value by the way of peltier effect. At this time, thermal flow along the sample and temperatures are measured by the heat flow meter and thermocouple located on the upper and lower plates of the device. When HFM provided thermal equilibrium and uniform temperature gradient, then, thermal conductivity is determined. The thermal conductivity measured by the HFM device is determined by the Fourier thermal conductivity equation below.

$\mathrm{q}=-\mathrm{kA} \frac{\Delta \mathrm{T}}{\Delta \mathrm{x}}$

In this equation, $\mathrm{q}\left(\mathrm{W} / \mathrm{m}^{2}\right)$ is heat flow, $\mathrm{k}(\mathrm{W} / \mathrm{mK})$ is thermal conductivity, $\mathrm{A}\left(\mathrm{m}^{2}\right)$ is area, $\Delta \mathrm{T}(\mathrm{K})$ is temperature difference and $\mathrm{x}(\mathrm{m})$ is sample thickness. HFM operates by measuring, recording and printing using this equation and the calibrated software. Before starting the experiments, the device was calibrated by using pyrex-7740, the thermal conductivity of which is known for some temperatures, and also by using a pyrex calibration file. In addition, the reliability of the results and repeatability of the measurements have been checked.

\section{Results}

\subsection{Physical tests}

The fibers obtained from different parts of the plant were analyzed according to their diameters through the use of an optical microscope and the results are given in the Table 2.

Table: 2 Diameter distribution and average diameter of the fibers

\begin{tabular}{lccc}
\hline & Max. Diam. & Min. Diam. & Mean \\
\hline 350AB & 63 & 29 & 45.57 \\
350AM & 47 & 20 & 34.84 \\
350AT & 32 & 13 & 21.03 \\
\hline
\end{tabular}

When the date in the table above are analyzed, it is seen that the fiber diameter decreases from the bottom to the top of the plant. The mean decrease rates according to the bottom part are -23.5 and -54 in percentages, respectively, from middle to the top part.

The results obtained from XRD images of the nettle fiber (Fig. 2) are given in Table 3. 
Table: 3 Crystalline ratios \% of the fibers

\begin{tabular}{llll}
\hline & I002 & Iam & CrI \\
\hline 350AB & 1007 & 262 & 73.98 \\
350AM & 1004 & 249 & 75.20 \\
350AT & 1140 & 278 & 75.61 \\
\hline
\end{tabular}

When the numerical values obtained are analyzed, it is seen that the fibers with the highest crystallinity index are obtained from the top part of the plant. Then the fibers obtained from the middle part and lastly the fibers obtained from the bottom part come. The change in the amount of crystalline is $1.65 \%$ and $2.20 \%$ in the middle and top parts, respectively, relative to the bottom.

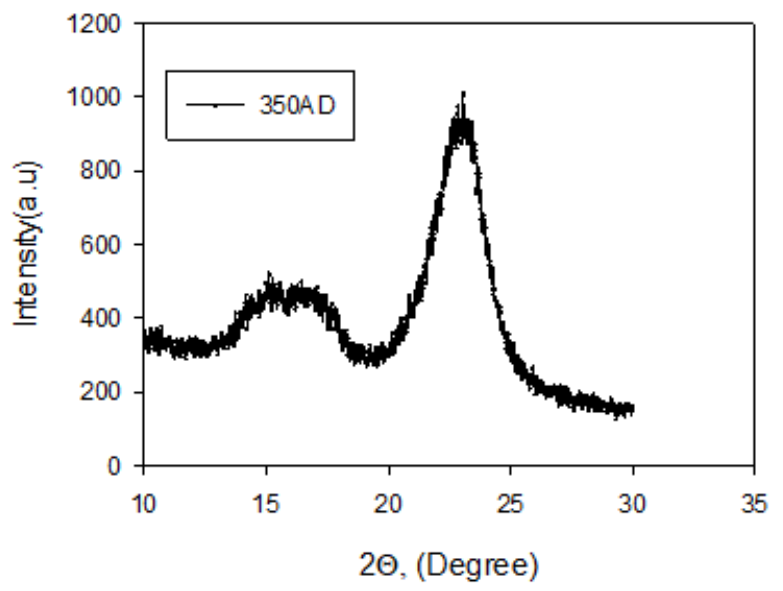

Fig. 2. XRD image of the fiber obtained from the bottom part of the plant grown at 350 altitude

Regular or irregular formation of the microstructure of the materials is one of the important factors affecting the density for the same materials. There is a linear relationship between the density of the materials and the crystallinity degrees [9]. In this study, when Table 3 and Table 4 are examined together, the presence of a linear relationship between the $\%$ crystallinity ratios of the materials and the densities can be easily noticed.

Table: 5 Density of the Fibers

\begin{tabular}{lc}
\hline Fiber Type & Density \\
\hline 350 Bottom & 1.1402246 \\
350 Middle & 1.1633373 \\
350 Top & 1.1888322 \\
\hline
\end{tabular}

\subsection{Determination of Thermal Conductivity ( $\lambda$ )}


The variation of the thermal conductivity of three different fibers with increasing fiber amount is given in Figure 3. When a comparison is made here according to the thermal conductivity of the matrix, the thermal conductivity of all composites decreased by $2.5 \%$. This decrease was $3.5 \%$ and $4.7 \%$ in the composites reinforced with the fibers obtained from the bottom, middle and top parts of the plant, respectively. It is estimated that this decrease was caused by the air voids formed at the beginning and end of the short fibers. It can be said that by the increase in the ratio, these voids were covered by the fibers and the contact between different fibers partially increased. This led to an increase in thermal conductivity. This increase started from $2.5 \%$ and went up to $10 \%$. As stated above, the increase in the amount of fibers increased the contact between the fibers, and this resulted in a slight increase in the thermal conductivity with the amount of fibers. When the increase rates of the thermal conductivity according to the matrix material were examined, the increase in the composites formed by fibers obtained from the bottom, middle and top parts were approximately 1,2 , and $3 \%$ respectively.

Stinging nettle fibers have a hollow structure like other natural fibers. The air in the voids has a low thermal conductivity value of $0.026 \mathrm{~W} / \mathrm{mK}$ at $25^{\circ} \mathrm{C}$. Probably, parallel to the change in the diameters, the diameter of the void in the single fiber also increases. It can be said that the thermal conductivity is lower in the composites formed by the fibers having more air due to the internal void. As seen in Figure 3, the composite obtained from the fibers of the bottom part have lower thermal conductivity than the composites obtained from the other parts. Moreover, both the density and crystallinity degrees of the fibers obtained from the bottom part of the plant are lower than those of the other parts. The reverse can be easily seen in the composites formed with the fibers of the top part. The thermal conduction of these composites is higher than that of the other parts. In general, the high rate of crystallinity of cellulosic materials affects their thermal properties. In this context, the highness of the crystallinity significantly increases the thermal conductivity [10].

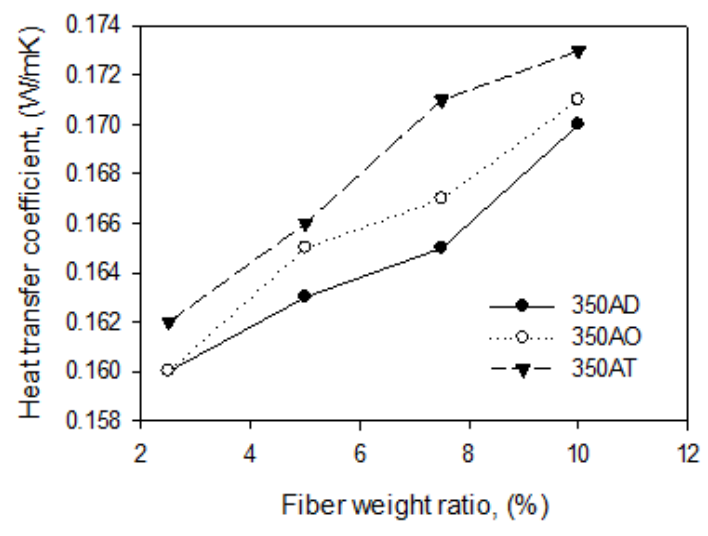

Fig. 3. The variation of the thermal conductivity of the fibers form three different parts

\subsection{Morphology}


The images of single nettle fiber are given in Fig. 4a and Fig. 4b. The diameter of the fiber in the image is $32.9 \mathrm{~m} \mu$. As stated in the physical properties, it is a fiber from the bottom part and its diameter is within the given measurements. In Fig.4b, a cross sectional view of a fiber bundle from the bottom part is shown. When the image is examined, the single fibers within the fiber bundle can be seen. It can be easily seen that the middle of the fiber is empty when the image of the single fiber visible on the top of the figure is analyzed.

Although the nettle fiber is in a hollow structure, the cellulose in the structure having a high crystallinity rate of $73.98 \%$ even at the bottom part, as stated above, partially increases the thermal conductivity of these fibers despite of the voids. This means that the crystalline structure is more effective in thermal conductivity.

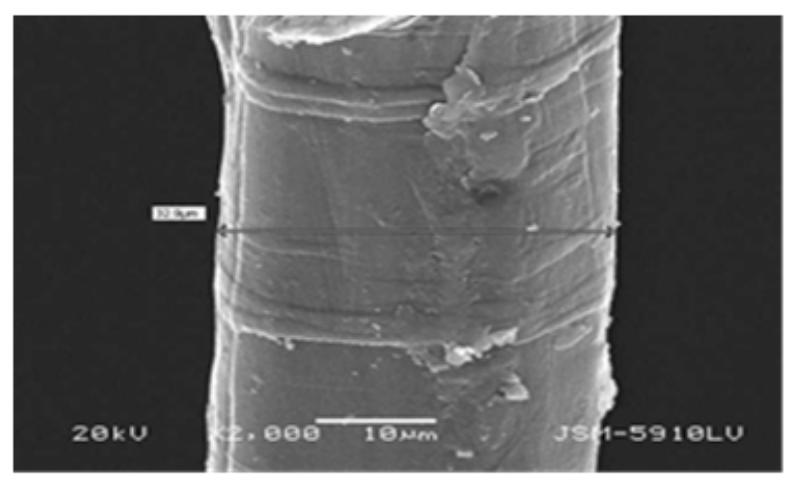

Fig.4a. SEM Image of the single nettle fiber

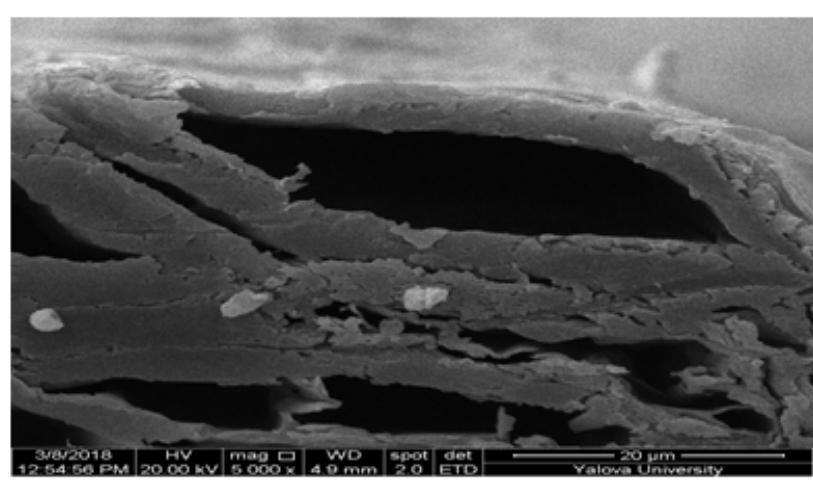

Fig.4b. The sectional view of fiber bundle

\section{Conclusions}

Choosing the fiber in the process of composite production is important if the composites to be produced with nettle fiber are used in thermal insulation. Therefore, it will be more effective to cut the plant into three and to use the fibers obtained from the bottom part. The selection to be made by taking the results of this study into consideration will make an important contribution to preventing the mixed type (bottom, middle, top) fiber selection. Thus, the negative effects of the fiber to be used in thermal conduction will be avoided, at least partially. It will also be possible to use the fibers from different parts in more accurate areas.

\section{Appendices}


Fig. A1

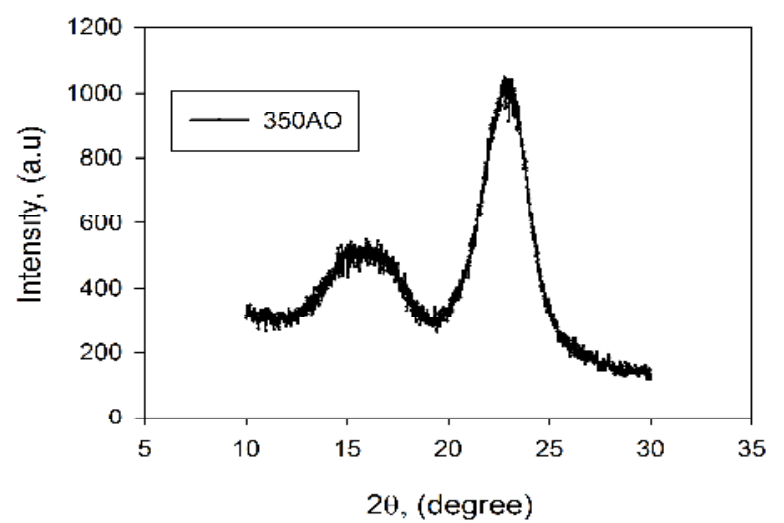

1.XRD graphics of the fibers obtained from middle part (JPG)

Fig. A2

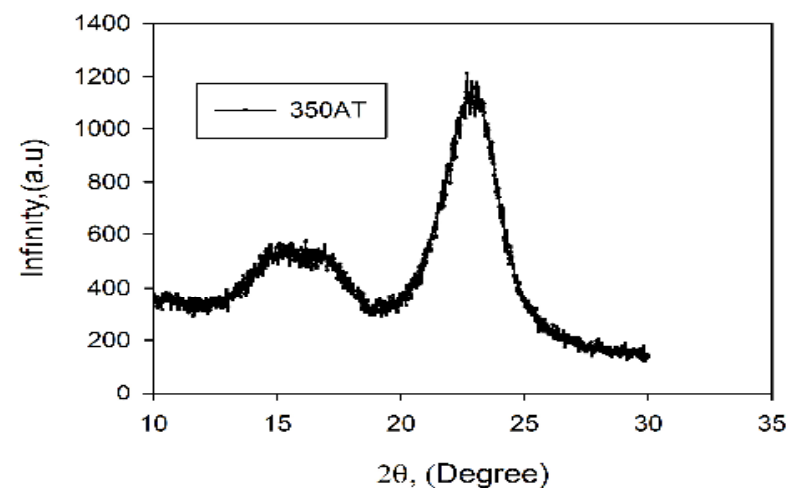

2.XRD graphics of the fibers obtained from top part (JPG)

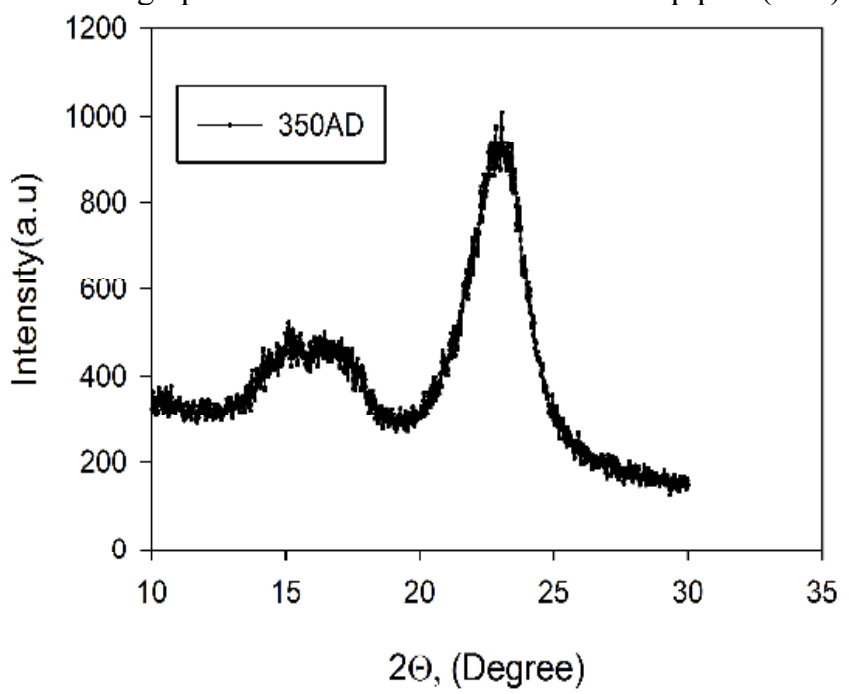

Fig. 2. XRD image of the fibers obtained from the bottom part of the plant grown at 350 altitude (JPG)

\section{References}


[1] Netravali AN. Advanced 'green' composites., Advanced Composite Materials, 2007;16(4):269-82.

[2] Summerscales J, Dissanayake PJN, Virk SA, Hall WA.. Review of bast fibres and their composites. Part 1-fibres as reinforcements. Composites Part A: Applied Science and Manufacturing 2010:41(10):1329-35.

[3] La Mantia, FP, Morreale M, Compos Part A, 2011 42: 579-88.

[4] Mangal R., Saxena NS, Sreekala MS, Thomas S, Singh, K. Thermal properties of pineapple leaf fiber reinforced compositesMaterials Science and Engineering A.2003:339: 281-85

[5] Onésippe C, Passe-Coutrin N, Toro F, Delvasto S, Bilba K, Arsène MA. Sugar cane bagasse fibres reinforced cement composites: Thermal considerations, Composites: Part A. 2010:41:549-56

[6] Qia C, Yadamab V, Guoa K, Wolcottb MP. Thermal conductivity of sorghum and sorghumthermoplastic composite panels, Industrial Crops and Products 45 (2013) 455- 460

[7] Osugi R, Takagi H, Liu K, Gennai Y. Thermal conductivity behavior of natural fiber-reinforced composites. In Proceedings of the Asian Pacific Conference for Materials and Mechanics, 2009. pp.163.

[8] www.camelyafresins.com(Poliya)

[9] Zhang T, Luo T. Role of chain morphology and stiffness in thermal conductivity of amorphous polymers. J Phys Chem B. 2016;120(4):803-812.

[10]. Edit. Lobo, H., Bonilka, Handbook of Plastics Analysıs, s.224, Mavcel Dekker inc. Newyork Basel 2003. 